\title{
Information management at the North Temperate Lakes Long-Term Ecological Research site - successful support of research in a large, diverse, and long running project
}

Corinna Gries $^{a}$, Mark R. Gahler ${ }^{a}$, Paul C. Hanson ${ }^{a}$, Tim K. Kratz ${ }^{a, b}$, Emily H. Stanley ${ }^{a}$

${ }^{a}$ Center for Limnology, University of Wisconsin, 680 North Park Street, Madison, WI 53706, USA; cgries@wisc.edu, gahler@wisc.edu, pchanson@wisc.edu,tkkratz@wisc.edu, ehstanley@wisc.edu

${ }^{\mathrm{b}}$ currently: National Science Foundation, 4201 Wilson Boulevard, Arlington, Virginia 22230, USA ; tkratz@nsf.gov

Corresponding author: Corinna Gries, Center for Limnology, University of Wisconsin, 680 North Park Street, Madison, WI 53706, cgries@wisc.edu 
Abstract

Information management has been an integral part of the research process at the North Temperate Lakes Long-Term Ecological Research (NTL LTER) program for over 30 years. A combination of factors has made the information management system (IMS) at NTL very successful. Significant resources have been invested in the IMS from the beginning, the Information Manager has been part of the leadership team at NTL and later in various roles at the LTER network level; the NTL IMS was a very early adopter of database systems, standardized metadata, and a data delivery system based on those metadata. This approach has made data easily accessible to NTL researchers and the broader scientific community. Data management workflows have become increasingly more automated with adoption of modern technologies as they became available, making the system efficient enough to handle core data as well as all one-time research data generated within NTL and several related projects. More than three decades of core data from eleven lakes are reused extensively as critical background information and as the limnological go-to site for many synthesis projects within and beyond LTER.

The NTL IMS continues to implement new technologies for improving data management efficiency, discovery, access, integration, and synthesis. Accordingly, the functionality of the original online data access system programmed in Java and JavaServer Pages (JSP) was ported to the modern content management system, Drupal and integrated into LTER'sDrupal Ecological Information Management System (DEIMS). NTL has invested in sensor technology for studying lake conditions over the long term, which necessitated a sophisticated management system tailored to high frequency data streams. Several technologies have been used at different times for automation of management, quality control and archiving of these high volume data. Near real time lake conditions can be accessed on the NTL website and smart phone Apps.

Easy access to long-term and sensor data in the NTL IMS has led NTL researchers to develop new analytical methods and the publication of several R statistical packages. Recent graduate students are now employed as data scientists helping to define a new career path inspired by the availability of data.

The NTL project has amassed one of the world's most comprehensive long term datasets on lakes and their surrounding landscapes. The NTL IMS facilitates the use of these data by multiple groups for research, education, and communication of science to the public.

Keywords: Ecological Information Management, Long-Term Ecological Research, database, sensor data, data life cycle.

\section{Introduction to NTL}

The North Temperate Lakes Long-Term Ecological Research (NTL ${ }^{1}$ LTER $^{2}$ https://lter.limnology.wisc.edu)program began in 1981 as one of six sites that formed the initial nodes of the LTER network funded by the National Science Foundation (NSF). Since then the network has grown to its current configuration of24 sites conducting long term research across a wide range of ecosystems (Waide \& Thomas, 2012). In its fourth decade and located

\footnotetext{
${ }^{1}$ NTL: North Temperate Lakes

${ }^{2}$ LTER: Long-Term Ecological Research Program
} 
in the state of Wisconsin, USA (Figure 1), NTL LTER studies the dynamics of temperate lakes in a landscape context and over time scales ranging from minutes, hours, days, and weeks to many decadesand even millennia (Magnuson et al., 2006). It is guided by the overarching research question, 'How do biophysical setting, climate, and land use and cover interact to shape lake dynamics and organization in the past, present and future?' Throughout its 30+ year history, the NTL LTER program has made significant progress in understanding long-term change in two suites of lakes in the Northern Highland Lake District (NHLD; northern Wisconsin) and the Yahara Lake District (YLD, southern Wisconsin) (Figure 1) along with their surrounding landscapes.

Figure 1

At the NTL LTER program, Information Management $\left(\mathrm{IM}^{3}\right)$ has been integrated into the research process from the very beginning of the project. In support of long-term research, the curation, storage, and reuse of data, i.e., IM, has been held to high rigor and standards that underlie the larger scientific effort. Although practices have changed throughout the past 30+ years, NTL IM has been guided by the goals of: (1) facilitating the scientific process; (2) applying appropriate technologies to enhance efficiency in data curation; (3) developing and following best practices for archiving and making data discoverable for future science; (4) actively seeking outside connections; (5) fostering an environment of experimentation and innovation. The IM team embraces the full data life cycle and is actively involved in promoting and supporting Open Science(Hampton et al., 2015) through providing appropriate technologies and training.

\section{History of Information Management at NTL}

NTL has collected, curated, and made publicly available over 250 data sets that include physical, chemical, biological, and socio-economic variables for the eleven main study lakes and their watersheds (Figure 2). These data are among the most complete long-term, multi-lake datasets in the world and provide the foundation for understanding long-term change in lakes and their surrounding landscapes. Included are core datasets- many of which began with project inception in 1981, results of short term investigations (most commonly from graduate research), manipulative experiments, larger regional studies, and some datasets that extend the long-term record by digitizing archived information as far back as the early 1900s.

Three decades of IM have seen many changes in technology as well as a major shift in the perception of why information management and open data exchange are valuable. Long-term core datasets have always been available to all participants for primary research to provide critical background information and for scaling of short term research results in time and space at NTL. Hence, the culture of data sharing was established from the beginning, with the Information Management System ( $\mathrm{IMS}^{4}$ ) striving to make data access as convenient as possible. In contrast, data from short term research projects have taken longer to fully capture and publish within the IMS. However, due to a change in research and data management culture, the habit of submitting data to the IMS is becoming more widespread. A major driver of this shift is the requirement by a growing number of journals to have data published in a stable repository before the research paper is published.

Figure 2

\footnotetext{
3 IM: Information Management

${ }^{4}$ IMS: Information Management System
} 
NTL embraced database technology early in its development, with data being stored in a hierarchical database on the campus mainframe as early as 1982 (Benson et al., 2006). During the first decade, NTL added data loggers, a local area network, and a bibliography database before moving the main database into the fully relational Oracle database system in 1993 . The next decade was marked by the rise of internet technology, and the first website, published in 1994, provided access to data and the site's bibliography. Researchers were trained in querying the central database using a commercial client application before sophisticated data queryingand download capability was added to the website in 1997 for climate datasets. Oracle was also used to store metadata- that is, data about the data. This allowed the rapid expansion of initial querying capabilities to all datasets stored in Oracle and added download capabilities for datasets generated in proprietary formats, specifically, from Geographic Information Systems and molecular analyses. A Java/JavaServer Pages web application based on these metadata replaced the desktop client application in 2001 and provided data access well beyond the participants of the NTL project. The principles of using standardized metadata held in a relational database to build a web application are still being used (see below). These highly structured metadata strongly contrasted the previous unstructured text documents describing the data, and their development proved to be a great foresight when the metadata standard, the Ecological Metadata Language (EML ${ }^{5}$ (Fegraus et al., 2005)) was adopted by the LTER network as a whole in 2002. Conforming to this new standard proved to be relatively easy and was accomplished by adding a few fields in the database and then exporting the data programmatically into the EML format- again, a procedure that is still implemented.

Throughout the history of NTL, the IM team has sought to improve efficiency through automation of quality control and data ingestion into the IMS. Given established workflows of the field and lab crews, it turned out that for most cases standardized Excel spreadsheets were the most effective means of transferring data to the IM team. Those data were then ingested into the database via Perl scripts and quality controlled with database triggers in Oracle. However, a few specific data entry applications have been developed which support better data quality, speed of sampling, or management of samples and results (MobileFish, Z3, and ChemLab; see below).

\section{Information Management Personnel}

Looking back over the 35-year history of the project, it is clear that the NTL IM effort has scaled with the scientific effort. It has been paramount that the skills and background of the information manager overlap those of the rest of the NTL team to provide for the effective integration of IM into the project. Over the years,members of the IM team have changed, but the team has always been led by an ecologist knowledgeable in information management who was able to communicate with ecologists, computer scientists, and informaticians. With minimal turnover, this person has provided leadership in developing an IMS that has served the site researchers well and successfully migrated it through emerging technologies. Other members of the team generally were more technically oriented and provided programming and systems administration skills. Student programmers were hired for specific projects.

This approach parallels that of the science and funding in NTL, with the vision for long term data collection developed by more senior personnel being supplemented with faster turnover by graduate students. On the IM side, long-term visioning and continuity provided by senior IM staff is supplemented by short-term contributions by undergraduate computer science students. This

\footnotetext{
${ }^{5}$ EML: Ecological Metadata Language; https://knb.ecoinformatics.org/\#external//emlparser/docs/index.html
} 
also reflects the realities of funding, with long-term continuity provided by LTER, and shorterterm projects provided by related grants.

\section{The Current Information Management System}

The majority of data life cycles at NTL start in the field. A field crew is responsible for core sample collection and processing and eventually data entry. Usually, quite a few steps are involved, from preparing the sample container, taking the sample, making measurements, and running analyses, to entering the data. These processes may take several months to complete. To support each individual workflow, the IM team has developed custom software, online data input applications or standardized spreadsheets, data processing scripts, and routines to upload the data into the central database. Once in the database, datasets are documented with metadata, which are stored in separate tables of the database. Upon metadata generation, the dataset is available for querying and download on the NTL website. Datasets and metadata are then submitted to the central LTER data repository(Michener et al., 2011), and from there, they are served to the data aggregator,DataONE (http://dataone.org/) (Michener et al., 2012). Hence, the same dataset may be discovered on the NTL website, the LTER data catalog, and the DataONE search interface. As a data aggregator,DataONE provides access to data from many providers, LTER being one of them.

There is no endgame in IM.It evolves through time, just like the science it supports. Although core monitoring methods and target variables have remained very stable over the past 30+ years at NTL, technology has changed. Analytical instruments have been modernized, instant read sensors have been added, and data processing scripts have been transferred to modern programming languages. The backend database system is now the open source MySQL. Over the years, web technology has undergone major changes and we currently use the open source Drupal content management system. Aside from field data, the NTL IMS handles data from spatial analyses for which metadata are created, but the data themselves are stored on the file system. They are submitted to the central LTER data repository as zipped shapefiles. Another group of data are streaming sensor data collected and managed at NTL.Below we describe elements and procedures of the data lifecycle currently in use in more detail.

\subsection{Computing Resources}

At the heart of the NTL computing and networking resources are a small group of main servers running Ubuntu Server (Linux) and Microsoft Windows Server operating systems. Each of the main servers is dedicated to provide specific functionality (database, website, file storage, backup, experimental software, testing, and production), and we connect to them with networked desktop computers using various client software. In the case of the Ubuntu servers, basic server administration is done with a command-line shell accessed via SSH client. The Ubuntu servers are the main workhorses, and Windows servers are maintained only because some software is Windows-compatible only. For example, the vendor software that communicates with the lake buoys is not available for Linux.

\subsection{Data Storage and Backup}

As we described earlier, NTL's current archive of digital scientific data consists of more than250 distinct, published and fully documented data sets. They cover temporal extents ranging from less than one year of data to records spanning over 100 years (one dataset spanning 550 years). Almost $50 \%$ are 'Short Term'; that is, five years or less (Figure 2). A working copy of all data is stored in a database that users can access and download through the Drupal website. The data (database and file system) are backed up in multiple locations, both locally and offsite. The off-site backup takes advantage of infrastructure provided by the University of Wisconsinand is kept in cloud storage using Box. When a new sampling or data collection cycle 
is completed (annually), a snapshot of the data is stored as Comma Separated Values (CSV) file included in the backups and uploaded to the central LTER data repository. This is done by a full export of the dataset from the database. In addition to being another form of backup, the website provides links which allows users to download the entire dataset without querying the database.

Facilitation of backups is mostly an automated process using the cron utility on Ubuntu, which is a task scheduler for commands and scripts. Backups are run nightly with a Unix shell script calling the MySQL command mysqldump followed by file compression on the result. A few times per week, additional scripts are run that back up a number of file directories.

\subsection{Metadata}

Data alone are useless for ecological research. Only when they are well-described by accompanying metadata are the data not only useable, they are also discoverable and thus stand a chance of being re-used for science beyond that which had driven their inception. The LTER Network as a whole agreed to adopt the Ecological Metadata Language (EML(Fegraus et al., 2005)), a specific XML (EXtensible Markup Language) Schema, as their metadata exchange format. Metadata, data describing the 'what, where, when, who, and how' of a dataset, need to be formatted according to that standard before the dataset and the metadata can be submitted to the central LTER data repository. EML was developed by the ecoinformatics community with input from LTER information managers and provides a flexible framework for storing and communicating information on authors, sampling methods, measurement units, and data structures (Jones et al., 2001). Even before EML was adopted by the LTER network, NTL had metadata stored in a database; i.e., already highly structured and standardized. With the addition of a few fields to hold content required by EML, it became straightforward to programmatically produce XML output from the database.

Standardizing the metadata format has led to a few advances such as the development of metadata editors, the capacity to perform data searches across a wide range of data providers, and automation of data access. Furthermore, it allows web services to receive and process requests in larger workflows meant to integrate multiple data sources. NTL used this approach for building an online data access, query and download application, originally in Java/JSP and now in Drupal since before the adoption of EML.

\subsection{The Drupal Environmental Information Management System (DEIMS)}

Traditional scientific data are one component of a broader IM system, and technologies have been adopted to link data, publications, people, and locations. The outcome is a rich collection of information that represents not only the data, but the people and places that are important to the scientific process. Drupal is an open source content management system which has been extended via custom modules to become an Environmental Information Management System (DEIMS; https://www.drupal.org/project/deims) (San Gil et al., 2010). 'Out-of-box' Drupal provides general website management tools, security and log-in credential management, content tagging, and different views of the content; however, with a very large and active developer community, additional modules are available for many more tasks. One great appeal of Drupal initially was that it provides convenient interlinking of information on the NTL website. Not only could people (NTL researchers) be connected to their publications and datasets, the interlinked web of information includes the study lakes (research sites) linked to datasets, datasets to research project descriptions and everything to NTL's main research questions and LTER core research areas. In other words, this allowed for a comprehensive display of research themes and activities at NTL, how NTL tackles its core questions, and on what research products transformative findings are based. Web access statistics show that these aspects of 
our website are second only to accessing data. This interlinked information gives visitors many entry points to finding what they are interested in, be it the research a particular person does, the dataset for which one only vaguely knows when, by whom, and what subject it was created, all data collected in one lake, or all datasets associated with one research theme.

A group of LTER sites has further developed DEIMS with custom modules generating valid EML (XML) files and facilitating data querying and data download (Gries et al., 2010; San Gil, 2011). Currently, modules for limited data graphing capabilities are being developed at NTL as well as real time display of current lake and weather conditions provided by instrumented buoys.

\subsection{Custom Technology at NTL}

Many information management tasks are accomplished by custom scripts that do not provide user friendly interfaces and are only used by the IM team. Most data are received by the IM personnel as standardized Excel spreadsheets. Some of the data can be directly submitted to the database, but most need some quality checking or further calculations, all of which is accomplished by such scripts. These scripts have undergone some evolution over the years, starting with Perl scripts run on a Unix server, the Kepler workflow system (Altintas et al., 2004), and now mostly scripts in the R statistical language (https://www.r-project.org/) are used for data manipulations. The original Perl scripts involved many manual steps of formatting Excel spreadsheet, moving data from the desktop Windows system to a Unix server and then employing Unix functionality for other tasks. In an effort to further automate these procedures we originally employed the Kepler workflow system which allowed us to integrate legacy code into an updated workflow (Gries and Porter, 2011). However, the R statistical language has a large user and contributor base and provides greater functionality for data processing. Although there is a certain amount of personal preference involved in choosing one language over another, R provides many advantages over Kepler, especially when $\mathrm{R}$ is used with the popular open-source Integrated Development Environment(IDE), R Studio. It is much simpler to generate code, comment code and graph intermediate and final results for visual quality control. However, there are several other modern languages that provide the same functionality and support (e.g., Python).

A few custom applications that are used by personnel other than the IM staff have been developed over the years to support sampling and analysis. These programs were developed by student programmers who were hired specifically for the task. They have graphical user interfaces for data entry and management and are generally much more robust than the simple data processing scripts. Three examples, MobileFish, Z3, and ChemLab are described below. Clearly, NTL has mostly chosen to develop this technology in-house over purchasing commercial systems. In particular, commercial versions of ChemLab (a Laboratory Information Management System or LIMS) are available. In the past, these off-the-shelf systems did not provide the needed functionality and costs are usually prohibitively high. But we are observing improvements in commercial products and they may eventually become a viable alternative to locally maintaining the code base for such a system. However, even a commercial system, especially one with great functionality, has a steep learning curve and requires expertise in using it. At this point it is not entirely clear where the optimum for return of investment lies along the spectrum of commercial solutions over custom in-house developments- and the optimal mix of the two may change over time.

MobileFish (https://software.Iter.limnology.wisc.edu/MobileFish)was developed as a field sampling app for handheld devices. This android application supports fish sampling and has improved data quality for fish measurements dramatically even in inclement weather and at night. It has important quality control mechanisms that alert the data entry person when, e.g., 
the fish length, weight, or the ratio of the two are out of range for a particular species, which is frequently caused by a decimal point error. It also counts the number of fish measured which helps the sampling crew adhere to the established protocol.

Z3 (https://software.Iter.limnology.wisc.edu/Z3)is a generic counting and measuring application that is used for zooplankton sample processing. It is applied as an overlay of a microscope image displayed on the computer screen. This overlay mode allows it to be used with cameras that don't support live video feeds except via their own driver or application window. The user defines the database structure and the export format, making this a very versatile application for counting and measuring organisms under a microscope.

ChemLabis an online $\mathrm{PHP}^{6}$ laboratory information management system for the Center for Limnology water chemistry laboratory. Users set up their samples and print barcodes. Then the analytical laboratory staff receives the labeled bottles and can enter analytical results for each sample. An approval and documentation of funding stream is built into the system as well as prioritization of samples based on due dates. NTL data are automatically transferred to the central database.However, the system is used more widely than only the NTL project, and individual users can track the progress of their samples as they are received, processed, and analyzed.

\section{From Manual Sampling to Sensor Technology}

High frequency sensor data entered the datastream at NTL in 2001 when the first instrumented lake buoy with a weather station and an underwater thermistor chain was installed. Campbell Scientific dataloggers use cell modems to communicate with the onshore network. Data are collected every minute and transmitted to an internet point of presence hourly. We currently deploy and maintain instrumented buoys on 5-7 lakes to monitor general lake conditions and as an essential tool for documenting changes induced by whole lake manipulations (e.g., see Shade et al., 2012).

Sensor networks have their own unique IM challenges, many of which are related to data flow paths, technological expertise required to support sensors, and increased data volumes (Porter et al., 2012). At NTL, sensors deployed with buoys are a hallmark of the kind of qualitative change to which IM has had to adapt. Sensors provide a frequency of measurements that enable quantification of important and transient physical phenomena (Read et al., 2012), as well as ecologicalprocesses such as metabolism that are emblematic of ecosystem function (Hanson et al., 2008). Data from sensors have placed IMs in a unique outreach role as well.At NTL, lake conditions are made available to the public in near-real-time. Local sailing clubs, fishers, and beach users have provided informal feedback on the importance of this information. Recently, a more direct form of outreach via sensor data has emerged from community interest in having daily predictions or forecasts for water clarity as an indicator of possible algal bloom development.NTL provides clarity estimates to the local lake association, the Clean Lakes Alliance, as part of their Lake Forecast web portal (http://lakeforecast.org).

\subsection{Data Management Challenges of Large(r) Volume Data}

One of the major challenges in environmental data management is the high degree of variability of the data. There are many methods to measure certain variables, the data are extremely context dependent, and each study tries to document this context with different parameters. This is especially true in a three dimensional body of water where samples may be depth

\footnotetext{
${ }^{6} \mathrm{PHP}:$ Hypertext Preprocessor; http://www.php.net/
} 
integrated or taken at discrete depth. Many different methods exist to determine something as seemingly straightforward as the nitrogen concentration in the water. High frequency sensor data add challenges in a different dimension, as the volume of data necessitates workflows that include a high degree of automation and IMs with software development skills. In contrast to many other environmental measurements, streaming data may be taken in a fairly standardized way, but require very different methods for quality control than manual measurements would. Campbell et al., (2013)have compiled the many different problems sensor data may have and suggest quality control approaches. Furthermore, these data are arriving at the IMS continuously and in near real time. In the past, NTL has used custom in-house software and the open source DataTurbine(Fountain et al., 2012) for managing the data stream from the data loggers and loading them into the database while applying seasonally adapted range checks for quality control.

While DataTurbine is a useful tool for handling sensor data streams, we are now using the commercially available Campbell Scientific

Loggernet(https://www.campbellsci.com/loggernet4)software in combination with custom $\mathrm{R}$ scripts to manage data collected at one-minute intervals from instrumented buoys on remote lakes in northern Wisconsin. The buoys each have Internet connectivity with a cellular modem. Loggernet, which is hosted on a server in southern Wisconsin, manages regularly-scheduled data collection by calling the buoy every hour and downloading data from the previous hour. Loggernet keeps track of what has been downloaded,hence, if a server-buoy connection cannot be made for some reason, the data can be retrieved during a later call. The data loggers on the buoys have enough on-board memory to hold several weeks' worth of data.

In addition to facilitating remote data downloads, Loggernet provides hooks in its software in which $R$ scripts are inserted into the data flow for custom formatting, range-checking (QA/QC), database insertion, and data-derived metrics (e.g.,depth of the thermocline (the transition layer between warmer mixed water at the lake's surface and cooler deep water below)). Each hour of data is written into the long-term archive, while the most recent weather and water data are made available to the NTL website and smartphone apps for public display of current lake conditions.

As much as the variability of environmental data and multitude of research questions present challenges for data preparation for synthesis research, sensor data lend themselves to applying standardizations during the data curation stage, i.e., formatting the data and loading them into a community-accepted data model with standardized terminology. Although pre-formatting the data represents more work at the curation stage, such harmonized data with standardized metadata allow for better data integration and more rapid analyses across many sites and different data providers. We use the Consortium of Universities for the Advancement of Hydrologic Sciences (CUAHSI) developed Observation Data Model (ODM, (Horsburgh et al., 2008)), and the data are submitted to the CUAHSI data center (https://www.cuahsi.org/wdc). The NTL website, however, also provides the data in the more idiosyncratic, site specific, format that site researcher have determined most useful for local analyses.

The high frequency and relatively standardized sensor data have led to broad collaborations and eventually to the founding of the international Global Lake Ecological Observatory Network (GLEON, see below). The accumulated data over space and time allow new techniques to be applied, such as wavelet analysis that enable patterns at multiple scales to emerge. The combination of rich data streams and new analytical tools are the raw material for generating new observations and inferences, and raising new questions about ecological patterns and processes in lakes. 


\section{Large Scale Data Synthesis Projects}

NTL's data have always been publicly available and were always used within the site for primary research and to provide a broader context for short term research results. Over time NTL has accumulated one of the morecomprehensive datasets of conditions in a suite of lakes and their surrounding landscape. These extensive data resources have allowed NTL researchers to address fundamental ecological questions regarding patterns and drivers of temporal dynamics across multiple scales and relationships between spatial and temporal ecosystem change (e.g., (Carey et al., 2016; Gergel et al., 1999; Hanson et al., 2006; Lottig and Carpenter, 2012). Beyond the specific geographic realm of NTL, these resources have inspired and been incorporated intoseveral large scale synthesis projects and promoted the development of a new skill set in students who are now employed as Data Scientists. This new skill set includes data mining, handling of large datasets, harmonizing highly variable data for collective analysis, developing analytical tools in various scripting language (primarily the R statistical language), and last but not least, the ability to collaborate with a wide range of international researchers(Cheruvelil et al., 2014; Goring et al., 2014).

NTL information management personnel have directly supported many aspects of data synthesis projects, making NTL data publicly available, formatting NTL data to enable harmonization with datasets from other sources, gathering and harmonizing data from many sources for analysis, consulting on final data product format, and finally, curating and publishing final data products for many projects. For example, the Global Lake Temperature Collaboration (Sharma et al., 2015) collated a large number of lake surface temperature time series from all over the world (O'Reilly et al., 2015). Publicly available NTL data were accessed by the investigators without specific IM involvement; however, support was provided for archiving this massive dataset. Metadata, originally written for the data paper, needed to be transformed into valid EML and additional metadata were necessary to describe data structures. The dataset then was published through the LTER Network Information System which is one of the recommended repositories (http://www.nature.com/sdata/data-policies/repositories) and provides stable Digital Object Identifiers (DOI).

Other synthesis efforts have been facilitated not only by the availability of NTL data, but also by IM personnel providing additional processing or manipulations of these data. In one case (the Under Ice Ecology group; Hampton et al., 2014), data needed to be extracted from the general NTL database and then reformatted into a highly complex structure that allowed its integrationinto a secondary database with global coverage. While time-consuming, the reformatting allowed temporally-detailed NTL data to be compared to other lakes that lacked the same degree of sampling resolution or duration. This example highlights a new challenge for IM across the LTER network. As data accumulate and become more accessible, synthesis has emerged as a potent mode of research (Carpenter et al., 2009). Requests for data use for these purposes are on the rise. Incorporation of site data into broad synthesis analyses inevitably requires some processing or manipulation. However, interested users may not be capable of doing this work in a timely fashion and will look to IM personnel for assistance. The dilemma that emerges is managing the trade-off between time spent facilitating the use of LTER data for specific projects versus the core mission requirements of continued provision of the database as a whole.

\subsection{The GLEON Connection}

In 2005, NTL researchers and information managers were instrumental in initiating the Global Lake Ecological Observatory Network (http://gleon.org/Weathers et al., 2013). This group 
envisioned a global network of hundreds of instrumented lakes distributed around the globe to understand at local, regional, continental, and global scale dynamicsof such issues as the direction and rate of change of lakes; the factors controlling daily, seasonal, and among-year variability of lake processes; and the reciprocal interactions between human use of lakes and lake ecology. This network has spurred many large scale data integrations in support of synthetic research initiated and carried out by diverse teams of researchers.

The synthetic nature of GLEON research, along with the international and diverse composition of the community, has presented both technological and social IM challenges. An initial attempt at centralizing data repositories from 50 GLEON members, based on an adaptation of the CUAHSI ODM technologies (Winslow et al., 2008)failed for a number of reasons.Different sites have different levels of available funding, information technology support, priorities for sharing data locally, and policies and procedures for making data available to researchers outside of the site.In recognition of these challenges, GLEON convened an Information Technology Task Force, whose responsibilities included working with the community to recommend policy and procedure changes to enable broader participation in both, the contribution of data, as well as the use and attribution of those data. The Task Force also recommended the development of a project tracking system to inform the community of ongoing research progress and to attribute credit to those providing resources, such as data.Finally, GLEON recognized the need to collaborate with outside 'big data' service providers, such as CUAHSI and DataONE, who have the human and technological resources to help federated research networks, such as GLEON, overcome IM barriers. This holistic approach to IM (i.e., managing information about people and places, along with information about data) has obvious parallels to LTER IM, and indeed, derives from LTER philosophy and technology. While IM evolves rapidly in GLEON, it remains an active area of discussion and policy development, and the focus of funding initiatives in support of a large community of lake ecologists.

\section{Future Directions}

In the life of the NTL LTER project environmentalinformation management and data sharing have always been a priority and a key ingredient in NTL research productivity, whileundergoing major paradigm shifts (Benson et al., 2006). Until relatively recently in the field of ecology, data were generally not shared with colleagues and resources were not invested in archiving data for later reuse, with the end result that data usually perished in drawers or on personal computers after a study was published (Michener, 2015). Through theconcept of core data which did not 'belong' to a single researcher, the vision of collecting long-term data beyond the career of a single investigator, and early adoption of server/client technology for data storage, NTL researchers were well ahead of their time in understanding the value of shared data.

Furthermore, as discrete datasets accumulated, it became clear that data integration needed to be better supported via improved database schemas and standardized keywording for describing the datasets and grouping them on the website.

These approaches and advancements have served NTL site research well. And through the central LTER data repository, DataONE, and GLEON,NTL's data is also a part of a larger and diverse collection of globally distributed datasets. This context made it obvious that terms in dataset titles, keywords, attribute names, etc. that were based on intimate and historic knowledge of NTL research were not meaningful outside NTL or even to new members of the NTL research team. Hence, another paradigm shift is needed that focuses on broader data and metadata integration for synthesis research that scales in time, space, across ecosystems, and local research themes. Now that LTER and many other datasets are easily accessible and well documented with rich metadata, we need to focus on making them more discoverable and 
usable without project-specific knowledge. This will require work on several levels. On the local data management level, awareness and implementation of standards developed and adoptedby a larger community are necessary. Datasets may have to be provided in different formats and submitted to more than one repository, e.g., the CUAHSI Hydrologic Information System or the USGS Water Quality Portal in addition to the LTER repository. On a more general level, the development and implementation of ontologies, semantic annotation and querying technologies must be developedbased on this enhanced information (Buttigieg et al., 2013; Madin et al., 2007; Williams et al., 2006).

Promoting Open Science is a stated goal of the NTL IM team; however, many developments are still needed to achieve the notion of a fully transparent research process. On the local level we are working with researchers to publish analytical code as a first step towards transparency. This involvesincreasing awareness and willingness through publications and presentations and providing training in using version control systems, writing reusable code, and researching how to best curate and archive code so that it becomes discoverable and reusable. On a broader level, user friendly technology is still needed to document analytical steps, produce reusable code and develop best practices and standards for curating code.

\section{Conclusions}

\section{Lessons learned}

- Setting up an efficient environmental information system requires significant dedicated resources and people with working knowledge in ecology, informatics, programming, and collaboration.

- Structured and standardized metadata have been instrumental at NTL in providing easy data access.

- Personnel turnover will introduce new and different technologies, which is good and bad. Updating old technology is desirable, but managing and maintaining a vast array of different technologies becomes a burden.

- Careful evaluation is necessary to decide between off-the-shelf commercial software and in-house developed custom solutions. Both have their place in an IMS.

- Similarly, collaborating with eco-informatics softwaredevelopment projects may require a change in local practices, but may in the long run advance overall efficiency.

- Environmental data are inherently heterogeneous and difficult to integrate for answering large scale questions. It is not clear yet where the optimum for the information management effort lies along the continuum from providing raw data in idiosyncratic formats (least data management effort) to standardized, aggregated and harmonized data (highest data management effort). The former is the most difficult to use, but has the highest flexibility for new recombinations, the latter allows for fast but limited analyses.

- Providing metadata content that supports data discovery on the local, thematic and highly aggregated level requires local knowledge as well as careful implementation of community developed standards.

IM for heterogeneous ecological data is still difficult. There are no substantive short cuts for making the data discoverable and useable for the broad community of potential data uses. Critical to NTL success has been the early recognition of the significance of IM, a corresponding commitment to/investment in supporting excellent IM personnel that has endured through the $30+$ years of project, and we suspect that this commitment will only expand further going 
forward in this new era of increased ease of data collection and increased interest in data use to understand the complex social-ecological dynamics of lakes in the landscape.

\section{Acknowledgements}

This material is based upon work supported by the National Science Foundation under Cooperative Agreement \#DEB-1440297, NTL LTER. Barbara Benson has guided the NTL IMS developments for most of the past 35 year and has collaborated with many others who have contributed greatly to its success. John J. Magnuson, the initial NTL LTER Principal Investigator understood the importance of IM 35 years ago and allocated substantial resources from the NTL budget. Stephen R. Carpenter embraced this fundamental tenet of NTL during his PI tenure.

\section{References}

Altintas, I., Berkley, C., Jaeger, E., Jones, M., Ludäscher, B., Mock, S., 2004. Kepler : An Extensible System for Design and Execution of Scientific Workflows, in: Proceedings of the 16th International Conference on Scientific and Statistical Database Management (SSDBM'04).

Benson, B.J., Hanson, P.C., Chipman, J.W., Bowser, C.J., 2006. Breaking the data barrier: Research facilitation through information management, in: Magnuson, J.J., Kratz, T.K., Benson, B.J. (Eds.), Long Term Dynamics of Lakes in the Landscape. Oxford University Press, pp. 259-279.

Buffam, I., Turner, M.G., Desai, A.R., Hanson, P.C., Rusak, J.A., Lottig, N.R., Stanley, E.H., Carpenter, S.R., 2011. Integrating aquatic and terrestrial components to construct a complete carbon budget for a north temperate lake district. Glob. Chang. Biol. 17, 11931211.

Buttigieg, P.L., Morrison, N., Smith, B., Mungall, C.J., Lewis, S.E., 2013. The environment ontology: contextualising biological and biomedical entities. J. Biomed. Semantics 4, 43. doi:10.1186/2041-1480-4-43

Campbell, J.L., Rustad, L.E., Porter, J.H., Taylor, J.R., Dereszynski, E.W., Shanley, J.B., Gries, C., Henshaw, D.L., Martin, M.E., Sheldon, W.M., Boose, E.R., 2013. Quantity is nothing without quality: automated QA/QC for streaming environmental sensor data. Bioscience 63, 574-585. doi:10.1525/bio.2013.63.7.10

Carey, C.C., Hanson, P.C., Lathrop, R.C., St. Amand, A.L., 2016. Using wavelet analyses to examine variability in phytoplankton seasonal succession and annual periodicity. J. Plankt. Res. 38 , 27-40. doi:10.1093/plankt/fbv116

Carpenter, S., Benson, B.J., Biggs, R., Chipman, J.W., Foley, J.A., Golding, S.A., Hammer, R.B., Hanson, P.C., Johnson, P.T., Kamarainen, A.M., Kratz, T.K., Lathrop, R.C., McMahon, K.D., Provencher, B., Rusak, J.A., Solomon, C.T., Stanley, E.H., Turner, M.G., Vander Zanden, M.J., Wu, C.H., Yuan, H., 2007. Understanding Regional Change: A Comparison of Two Lake Districts. Bioscience 57, 323-335.

Carpenter, S.R., Armbrust, E.V., Arzberger, P.W., Chapin, F.S., Elser, J.J., Hackett, E.J., Ives, A.R., Kareiva, P.M., Leibold, M. a., Lundberg, P., Mangel, M., Merchant, N., Murdoch, W.W., Palmer, M. a., Peters, D.P.C., Pickett, S.T. a., Smith, K.K., Wall, D.H., Zimmerman, A.S., 2009. Accelerate Synthesis in Ecology and Environmental Sciences. Bioscience 59, 699-701.

Cheruvelil, K.S., Soranno, P.A., Weathers, K.C., Hanson, P.C., Goring, S.J., Filstrup, C.T., Read, E.K., 2014. Creating and maintaining high-performing collaborative research teams: The importance of diversity and interpersonal skills. Front. Ecol. Environ. 12, 31-38.

Fegraus, E.H., Andelman, S., Jones, M.B., Schildhauer, M., 2005. Maximizing the Value of Ecological Data with Structured Metadata: An Introduction to Ecological Metadata 
Language (EML) and Principles for Metadata Creation. Bull. Ecol. Soc. Am. 86, 158-168. doi:10.1890/0012-9623(2005)86[158:MTVOED]2.0.CO;2

Fountain, T., Tilak, S., Shin, P., Nekrasov, M., 2012. The Open Source DataTurbine Initiative: Empowering the Scientific Community with Streaming Data Middleware. Bull. Ecol. Soc. Am. 93, 242-252. doi:10.1890/0012-9623-93.3.242

Gergel, S.E., Turner, M.G., Kratz, T.K., 1999. Dissolved Organic Carbon as an Indicator of the Scale of Watershed Influence on Lakes and Rivers. Ecol. Appl. 9, 1377. doi:10.2307/2641403

Goring, S.J., Weathers, K.C., Dodds, W.K., Soranno, P. a., Sweet, L.C., Cheruvelil, K.S., Kominoski, J.S., Rüegg, J., Thorn, A.M., Utz, R.M., 2014. Improving the culture of interdisciplinary collaboration in ecology by expanding measures of success. Front. Ecol. Environ. 12, 39-47. doi:10.1890/120370

Gries, C., Porter, J.H., 2011. Moving from custom scripts with extensive instructions to a workflow system: Use of the Kepler workflow engine in environmental information management, in: Gries, C., Jones, M.B. (Eds.), Environmental Information Management (EIM) Conference. University of California, Santa Barbara, CA, pp. 70-75. doi:10.5060/D2NC5Z4X

Gries, C., San Gil, I., Vanderbilt, K.L., Garrit, H., 2010. Drupal developments in the LTER Network. LTER Databits Spring.

Hampton, S.E., Anderson, S.S., Bagby, S.C., Gries, C., Han, X., Hart, E.M., Jones, M.B., Lenhardt, W.C., MacDonald, A., Michener, W.K., Mudge, J., Pourmokhtarian, A., Schildhauer, M.P., Woo, K.H., Zimmerman, N., 2015. The Tao of open science for ecology. Ecosphere 6, art120. doi:10.1890/ES14-00402.1

Hampton, S.E., Moore, M. V., Ozersky, T., Stanley, E.H., Polashenski, C.M., Galloway, A.W.E., 2014. Heating up a cold subject: Prospects for under-ice plankton research in lakes. J. Plankton Res. 37, 277-284.

Hanson, P.C., Carpenter, S.R., Armstrong, D.E., Stanley, E.H., Kratz, T.K., 2006. Lake dissolved inorganic carbon and dissolved oxygen: changing drivers from days to decades. Ecol. Monogr. 76, 343-363. doi:10.1890/0012-9615(2006)076[0343:LDICAD]2.0.CO;2

Hanson, P.C., Carpenter, S.R., Kimura, N., Wu, C., Cornelius, S.P., Kratz, T.K., 2008. Evaluation of metabolism models for free-water dissolved oxygen methods in lakes. Limnol. Oceanogr. Methods 6, 454-465.

Horsburgh, J.S., Tarboton, D.G., Maidment, D.R., Zaslavsky, I., 2008. A relational model for environmental and water resources data. Water Resour. Res. 44, 1-12. doi:10.1029/2007WR006392

Jones, M.B., Berkley, C., Bojilova, J., Schildhauer, M., 2001. Managing scientific metadata. IEEE Internet Comput. 5, 59-68. doi:10.1109/4236.957896

Lottig, N.R., Carpenter, S.R., 2012. Interpolating and forecasting lake characteristics using longterm monitoring data. Limnol. Oceanogr. 57, 1113-1125. doi:10.4319/lo.2012.57.4.1113

Madin, J., Bowers, S., Schildhauer, M., Krivov, S., Pennington, D., Villa, F., 2007. An ontology for describing and synthesizing ecological observation data. Ecol. Inform. 2, 279-296. doi:10.1016/j.ecoinf.2007.05.004

Magnuson, J.J., 2000. Historical Trends in Lake and River Ice Cover in the Northern Hemisphere. Science (80-. ). 289, 1743-1746. doi:10.1126/science.289.5485.1743

Magnuson, J.J., Kratz, T.K., Benson, B.J., 2006. Long-term Dynamics of Lakes in the Landscape: Long-term Ecological Research on North Temperate Lakes. Oxford University Press.

Michener, W.K., 2015. Ecological data sharing. Ecol. Inform. 29, 33-44. doi:10.1016/j.ecoinf.2015.06.010

Michener, W.K., Allard, S., Budden, A., Cook, R.B., Douglass, K., Frame, M., Kelling, S., Koskela, R., Tenopir, C., Vieglais, D. a., 2012. Participatory design of DataONE-Enabling 
cyberinfrastructure for the biological and environmental sciences. Ecol. Inform. 11, 5-15. doi:10.1016/j.ecoinf.2011.08.007

Michener, W.K., Porter, J., Servilla, M., Vanderbilt, K., 2011. Long term ecological research and information management. Ecol. Inform. 6, 13-24. doi:10.1016/j.ecoinf.2010.11.005

O'Reilly, C.M., Sharma, S., Gray, D.K., Hampton, S.E., Read, J.S., Rowley, R.J., Schneider, P., Lenters, J.D., Mclntyre, P.B., Kraemer, B.M., Weyhenmeyer, G.A., Straile, D., Dong, B.,

Adrian, R., Allan, M.G., Anneville, O., Arvola, L., Austin, J., Bailey, J.L., Baron, J.S., Brookes, J.D., de Eyto, E., Dokulil, M.T., Hamilton, D.P., Havens, K., Hetherington, A.L., Higgins, S.N., Hook, S., Izmest'eva, L.R., Joehnk, K.D., Kangur, K., Kasprzak, P., Kumagai, M., Kuusisto, E., Leshkevich, G., Livingstone, D.M., MacIntyre, S., May, L., Melack, J.M., Mueller-Navarra, D.C., Naumenko, M., Noges, P., Noges, T., North, R.P., Plisnier, P.-D., Rigosi, A., Rimmer, A., Rogora, M., Rudstam, L.G., Rusak, J.A., Salmaso, N., Samal, N.R., Schindler, D.E., Schladow, S.G., Schmid, M., Schmidt, S.R., Silow, E., Soylu, M.E., Teubner, K., Verburg, P., Voutilainen, A., Watkinson, A., Williamson, C.E., Zhang, G., 2015. Rapid and highly variable warming of lake surface waters around the globe. Geophys. Res. Lett. 42, n/a-n/a. doi:10.1002/2015GL066235

Porter, J.H., Hanson, P.C., Lin, C.-C., 2012. Staying afloat in the sensor data deluge. Trends Ecol. Evol. 27, 121-9. doi:10.1016/j.tree.2011.11.009

Read, J.S., Hamilton, D.P., Desai, A.R., Rose, K.C., Maclntyre, S., Lenters, J.D., Smyth, R.L., Hanson, P.C., Cole, J.J., Staehr, P.A., Rusak, J.A., Pierson, D.C., Brookes, J.D., Laas, A., $\mathrm{Wu}, \mathrm{C} . \mathrm{H}$., 2012. Lake-size dependency of wind shear and convection as controls on gas exchange. Geophys. Res. Lett. 39.

San Gil, I., 2011. The Drupal Ecological Information Management System (DEIMS): recent progress and upcoming challenges for a grassroots project. LTER Databits Fall.

San Gil, I., White, M., Melendez, E., Vanderbilt, K., 2010. Case Studies of Ecological Integrative Information Systems: The Luquillo and Sevilleta Information Management Systems, in: Sánchez-Alonso, S., Athanasiadis, I.N. (Eds.), Case Studies of Ecological Integrative Information Systems. Springer-Verlag, pp. 18-35.

Shade, A., Read, J.S., Youngblut, N.D., Fierer, N., Knight, R., Kratz, T.K., Lottig, N.R., Roden, E.E., Stanley, E.H., Stombaugh, J., Whitaker, R.J., Wu, C.H., McMahon, K.D., 2012. Lake microbial communities are resilient after a whole-ecosystem disturbance. ISME J. 6, 21532167.

Sharma, S., Gray, D.K., Read, J.S., O'Reilly, C.M., Schneider, P., Qudrat, A., Gries, C., Stefanoff, S., Hampton, S.E., Hook, S., Lenters, J.D., Livingstone, D.M., McIntyre, P.B., Adrian, R., Allan, M.G., Anneville, O., Arvola, L., Austin, J., Bailey, J., Baron, J.S., Brookes, J., Chen, Y., Daly, R., Dokulil, M., Dong, B., Ewing, K., de Eyto, E., Hamilton, D., Havens, K., Haydon, S., Hetzenauer, H., Heneberry, J., Hetherington, A.L., Higgins, S.N., Hixson, E., Izmest'eva, L.R., Jones, B.M., Kangur, K., Kasprzak, P., Köster, O., Kraemer, B.M., Kumagai, M., Kuusisto, E., Leshkevich, G., May, L., MacIntyre, S., Müller-Navarra, D., Naumenko, M., Noges, P., Noges, T., Niederhauser, P., North, R.P., Paterson, A.M., Plisnier, P.-D., Rigosi, A., Rimmer, A., Rogora, M., Rudstam, L., Rusak, J.A., Salmaso, N., Samal, N.R., Schindler, D.E., Schladow, G., Schmidt, S.R., Schultz, T., Silow, E.A., Straile, D., Teubner, K., Verburg, P., Voutilainen, A., Watkinson, A., Weyhenmeyer, G.A., Williamson, C.E., Woo, K.H., 2015. A global database of lake surface temperatures collected by in situ and satellite methods from 1985-2009. Sci. data 2, 150008. doi:10.1038/sdata.2015.8

Waide, R.B., Thomas, M., 2012. Long-Term Ecological Research Network, in: John Orcutt (Ed.), Earth System Monitoring: Selected Entries from the Encyclopedia of Sustainability Science and Technology. Springer Science \& Business Media, pp. 233-268.

Weathers, K., Hanson, P.C., Arzberger, P., Brentrup, J., Brookes, J., Carey, C.C., Gaiser, E., Hamilton, D.P., Hong, G.S., Ibelings, B.W., Istvanovics, V., Jennings, E., Bomchul, K., 
Kratz, T., Lin, F.-P., Muraoka, K., O`Reilly, C., Piccolo, C., Ryder, E., Zhu, G., 2013. The Global Lake Ecological Observatory Network (GLEON): the evolution of grassroots network science. Limnol. Oceanogr. Bull. 22, 71-73.

Webster, K.E., Kratz, T.K., Bowser, C.J., Magnuson, J.J., Rose, W.J., 1996. The influence of landscape position on lake chemical responses to drought in northern Wisconsin. Limnol. Oceanogr. 41, 977-984.

Williams, R.J., Martinez, N.D., Golbeck, J., 2006. Ontologies for ecoinformatics. Web Semant. 4, 237-242. doi:10.1016/j.websem.2006.06.002

Winslow, L.A., Benson, B.J., Chiu, K.E., Hanson, P.C., Kratz, T.K., 2008. Vega: A Flexible Data Model for Environmental Time Series Data, in: Ecological Information Management Conference. pp. 166-171. 
Figures

Figure 1:Map of NTL locations within North America and Wisconsin

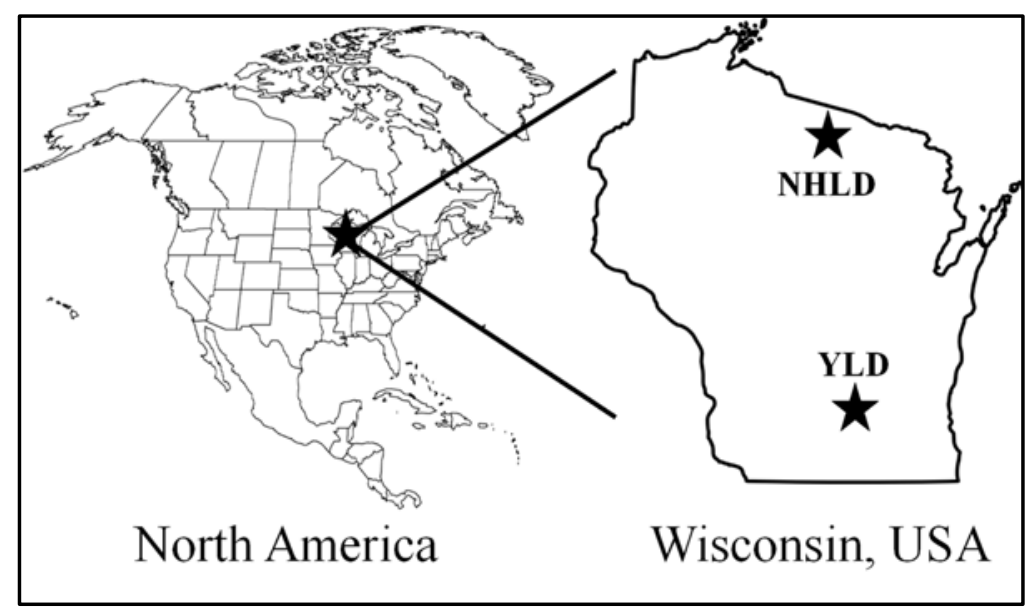


Figure 2: Datasets are counted in the year they start. Numbers for 1980 represent datasets starting prior to NTL. 'Core Datasets' are collected by the field personnel, 'Other Long Term Datasets' have been collected for specific purposes (e.g., harmonized climate station data, digitized historic data), 'Short Term Datasets' ( $\leq 5$ years duration) are from related research projects with separate funding or graduate research.

The numbered arrows mark publication of transformative research results based on long-term data:

1. LAKES IN THE LANDSCAPE: NTL researchers developed the "lake landscape position" concept to explain spatial variability in water chemistry and community composition that results from a shifting balance of groundwater, surface water, and precipitation inputs to adjacent lakes (Webster et al., 1996).

2. TRACKING ICE COVER: Synthesis of long-term records of lake and river ice duration throughout the Northern Hemisphere provided evidence that freshwater ecosystems are responding to climate change over the past 150 years (Magnuson, 2000)

3. MANAGING WATER QUALITY IN A CHANGING WORLD: Eutrophication, the overenrichment of freshwaters with nutrients, is caused by complex interactions of people and ecosystems that are hard to manage. A long-term perspective shows how management can adapt to changing social and ecological realities, learning from failures and building on successes (Carpenter et al., 2007).

4. CARBON STORAGE: Lakes and wetlands are overlooked components of regional and global carbon cycling, but in water-rich regions such as Wisconsin's Northern Highland Lake District, these ecosystems can store over $80 \%$ of the organic carbon despite covering less than 35\% of the landscape (Buffam et al., 2011).

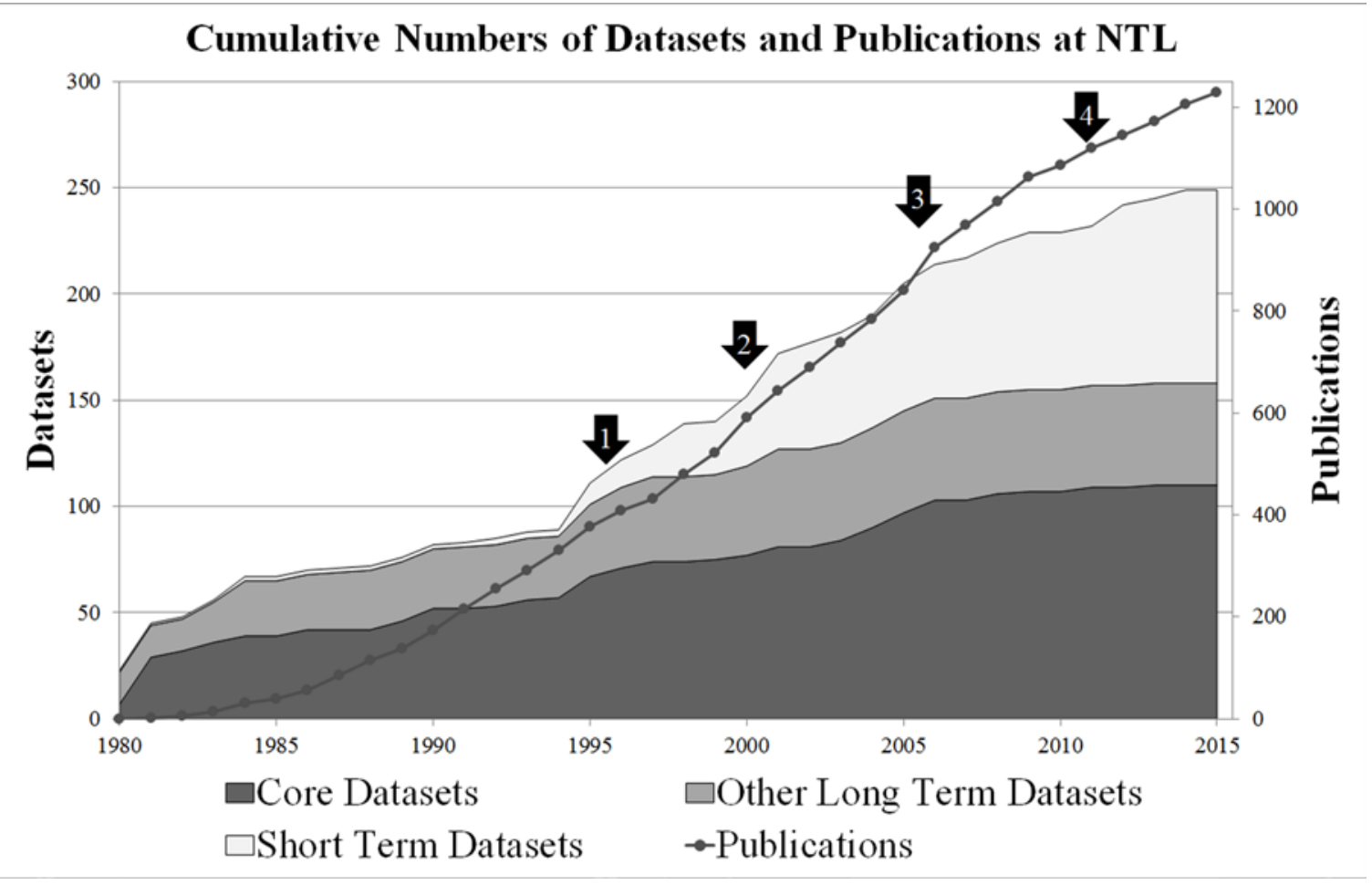

